\title{
Transplanted Beta Cell Response to Increased Metabolic Demand Changes in Beta Cell Replication and Mass
}

\author{
Eduard Montaña, Susan Bonner-Weir, and Gordon C. Weir \\ Research Division, Joslin Diabetes Center and the Department of Medicine, New England Deaconess Hospital and Brigham and \\ Women's Hospital, Harvard Medical School, Boston, Massachusetts 02215
}

\begin{abstract}
We determined the capacity of transplanted beta cells to modify their replication and mass when stimulated by changes in metabolic demand. Five groups of Lewis rats were studied: group 1 (Tx-Px) had a 95\% pancreatectomy $14 \mathrm{~d}$ after transplantation of 500 islets; group 2 ( Px-Tx) had a 95\% pancreatectomy $14 \mathrm{~d}$ before transplantation of 500 islets; group 3 ( Tx) was transplanted with 500 islets; group $4(P x)$ had a 95\% pancreatectomy; and group 5 (normal) was neither transplanted nor pancreatectomized. Blood glucose was normal in Tx-Px and Tx groups at all times. Px-Tx and Px groups developed severe hyperglycemia after pancreatectomy that was corrected in PxTx group in $\mathbf{8 3} \%$ of rats $28 \mathrm{~d}$ after transplantation. Replication of transplanted beta cells increased in Tx-Px $(1.15 \pm 0.12 \%)$ and Px-Tx (0.85 $\pm 0.12 \%)$ groups, but not in $T x$ group $(0.64 \pm 0.07 \%)$ compared with normal pancreatic beta cells $(0.38 \pm 0.05 \%)(P<0.001)$. Mean beta cell size increased in Tx-Px $\left(311 \pm 14 \mu \mathrm{m}^{2}\right)$ and Px-Tx (328 $\left.\pm 13 \mu \mathrm{m}^{2}\right)$ groups compared with Tx $\left(252 \pm 12 \mu \mathrm{m}^{2}\right)$ and normal $\left(239 \pm 9 \mu \mathrm{m}^{2}\right)$ groups $(P<0.001)$. Transplanted beta cell mass increased in Tx-Px $(1.87 \pm 0.51 \mathrm{mg})$ and $P x-T x(1.55 \pm 0.21 \mathrm{mg})$ groups compared with Tx group $(0.78 \pm 0.17 \mathrm{mg})(P<0.05)$. In summary, changes in transplanted beta cells prevented the development of hyperglycemia in Tx-Px rats. Transplanted beta cells responded to increased metabolic demand increasing their beta cell mass. (J. Clin. Invest. 1994. 93:1577-1582.) Key words: diabetes $\bullet$ islet transplantation $\bullet$ beta cell growth $\bullet$ beta cell mass - pancreatectomy
\end{abstract}

\section{Introduction}

The first successful transplants of islet cells in diabetic patients have been reported recently (1-4). However, restoration of normoglycemia is often not achieved or has limited duration. The causes of the limited survival of transplanted islets in diabetic patients and in large animals ( 5 ) are not well understood. In addition to rejection, nonimmunological factors could play a role in these poor outcomes. For example, impaired growth capacity of transplanted islets could lead to a decline in beta cell mass and contribute to graft failure.

Address correspondence to Dr. Eduard Montaña, Endocrine Unit ( 132), Hospital Universitari de Bellvitge, 08907 L'Hospitalet de Llobregat, Barcelona, Spain.

Received for publication 30 August 1993 and in revised form 3 December 1993.

J. Clin. Invest.

(c) The American Society for Clinical Investigation, Inc.

$0021-9738 / 94 / 04 / 1577 / 06 \$ 2.00$

Volume 93, April 1994, 1577-1582
A major problem in islet transplantation is obtaining sufficient mass of islet tissue for transplantation. A critical islet mass must be transplanted to achieve normoglycemia, with continued success being dependent upon the number of initially transplanted islets (6-8). Moreover, the islet mass needed for islet transplantation is higher that predicted on the basis of beta cell measurements in diabetes (9). An unknown factor in these considerations in the growth capacity of transplanted islets. Although some information about growth of transplanted islets has been obtained over the past decade (1016), neither specific beta cell replication nor beta cell mass have been determined. The implications of changes in beta cell replication can only be understood when beta cell mass is also taken into account.

We have shown that, in short-term successful islet transplants, basal nonstimulated replication of transplanted beta cells is similar to that of endogenous pancreatic beta cells (17). The aim of this study was to determine the capacity of transplanted beta cells to modify their replication and mass when stimulated by changes in metabolic demand. We have used the partial pancreatectomy model (18-21) to create a situation of increased metabolic demand in rats with islet transplants in order to determine the beta cell replicative capacity and the changes of the transplanted beta cell mass.

\section{Methods}

Male Lewis rats (Harlan Sprague Dawley, Inc., Indianapolis, IN) were obtained at 5 wk of age. Rats were transplanted with 500 syngeneic islets under the kidney capsule, and/or underwent a 95\% pancreatectomy according to the protocol described below. Animals were bled and weighed on the day of transplantation, day of pancreatectomy, and at least on days $2,5,7,10,14,18,21,25$, and 28 after transplantation and/or pancreatectomy. Blood glucose, determined between 9 and 11 a.m. in nonfasting conditions, was obtained from the snipped tail with a heparinized microcapillary tube, and glucose was measured with a portable glucose meter (Accu-Check II; Boehringer Mannheim Biochemicals, Indianapolis, IN). Animals were kept under conventional conditions in climatized rooms with free access to tap water and standard pelleted food.

Animal groups. Five experimental groups were studied (Table I). Group $1(n=7)$ : rats were transplanted and $14 \mathrm{~d}$ later underwent a 95\% pancreatectomy (Tx-Px group); grafts and pancreatic remnants were harvested $28 \mathrm{~d}$ after transplantation. Group $2(n=12)$ : a $95 \%$ pancreatectomy was performed and rats were transplanted $14 \mathrm{~d}$ later (Px-Tx group); grafts and pancreatic remnants were harvested 14 ( $n$ $=6)$ or $28(n=6) \mathrm{d}$ after transplantation. Group $3(n=13)$ : rats were transplanted and grafts and pancreas were harvested $14(n=6)$ or $28(n$ $=6$ ) d later ( Tx group). Group $4(n=6)$ : rats underwent $95 \%$ pancreatectomy and pancreatic remnants were harvested $14 \mathrm{~d}$ later (Px group). Group $5(n=6)$ : normal animals that had their pancreases removed (normal group). The beta cell mass of 7 groups of 500 islets isolated on different days was also determined. Since beta cell replication decreases with age (22), pancreatectomized groups were matched for age at pancreatectomy (groups 1, 2, and 4) (7-8 wk old), and 


\begin{tabular}{lrllll}
\hline \multicolumn{1}{c}{ Group } & $n$ & \multicolumn{1}{c}{ Day 0 } & \multicolumn{1}{c}{ Day 14 } & Day 28 & Day 42 \\
\hline $1(\mathrm{Tx}-\mathrm{Px})$ & 7 & Transplantation & Pancreatectomy & Harvest & Harvest (6) \\
$2(\mathrm{Px}-\mathrm{Tx})$ & 12 & Pancreatectomy & Transplantation & Harvest (6) & Harvest (7) \\
$3(\mathrm{Tx})$ & 13 & Transplantation & Harvest (6) & - & - \\
$4(\mathrm{Px})$ & 6 & Pancreatectomy & Harvest & - & - \\
$5($ Normal) & 6 & Harvest & - & \\
\hline
\end{tabular}

Day 0 denotes the day when the first experimental procedure was performed in each group. Groups 1, 2, and 4 were matched for age at pancreatectomy and groups 3 and 5 had were matched for age at harvest with groups 1 and 4 , and group 2 at day 28 . Figures in parentheses in groups 2 and 3 show number of animals harvested at each time point.

groups 3 and 5 had the same age at harvest as groups 1 and 4 . Rats were transplanted with islets from 5-7-wk-old animals.

Islet isolation and transplantation. The method for islet isolation and transplantation has been previously described for mice (17). Briefly, under sodium amobarbital anesthesia, pancreases were distended with $6 \mathrm{ml}$ of cold $\left(4^{\circ} \mathrm{C}\right) \mathrm{M}-199$ medium (GIBCO BRL, Gaithersburg, MD) containing $2 \mathrm{mg} / \mathrm{ml}$ of collagenase (Collagenase from Clostridium Histoliticum; Serva, Heidelberg, Germany), excised, and incubated in a stationary bath at $37^{\circ} \mathrm{C}$. The islets were separated by a density gradient (Histopaque-1077; Sigma Chemical Co., St. Louis, MO) and isolated islets were hand picked under a stereomicroscope two or three times until a population of pure islets was obtained. Only islets $>75$ and $<250 \mu \mathrm{m}$ in diameter were collected. With this restriction the final yield was $200-250$ islets per pancreas. The islets were transplanted under the kidney capsule of the left kidney on the day of the isolation using a $200-\mu$ l pipette tip previously plugged with Gelfoam ${ }^{\otimes}$ (Upjohn, Kalamazoo, MI).

Pancreatectomy. Partial pancreatectomy (95\%) was performed in 7-8-wk-old rats as previously described (18). In brief, animals were anesthetized with sodium amobarbital and $95 \%$ of the pancreas was removed by gentle abrasion with cotton applicators, being careful to leave major blood vessels intact. The pancreatic remnant was the tissue between the common bile duct and the first loop of the duodenum. Particular attention was placed on removing the small flap of pancreas attached to the pylorus. Nonpancreatectomized animals did not undergo any sham operation.

Graft and pancreas removal. On the day of graft removal rats were injected with 5-bromo-2'deoxyuridine $(\mathrm{BrdU})^{1}$ (Sigma Chemical Co.), $100 \mathrm{mg} / \mathrm{kg}$ i.p. body weight, and $6 \mathrm{~h}$ later the graft was removed. The kidney capsule surrounding the graft was incised and removed with the graft. Usually all the graft was removed with the capsule; whenever the grafted islets were infiltrating the kidney cortex a second piece of tissue was also taken to ensure that the entire graft was harvested. The grafts were fixed in Bouin's solution and processed for plastic embedding. The weight of the graft was determined on a balance reading to $0.01 \mathrm{mg}$ (A240; Mettler Instrument Corp., Hightstown, NJ) as described (17). Immediately after graft removal, rats were killed and the pancreas or the pancreatic remnants were excised, blotted, weighed, and fixed in Bouin's solution. Subsequently, the pancreatic tissue was embedded in paraffin.

Immunocytochemistry. Sections of graft and pancreas were double stained for BrdU and for the endocrine nonbeta cells of the islets with immunoperoxidase. Immunostaining for BrdU used a cell proliferation kit (Amersham International, Amersham, UK). Staining for the endocrine nonbeta cells used a cocktail of antibodies: rabbit anti-bovine glucagon (final dilution, 1:3,000; gift of Dr. M. Appel, University of Massachusetts Medical School), rabbit antisynthetic somatostatin (final dilution, 1:300; made in our own laboratory), and rabbit antibovine pancreatic polypeptide, final dilution, 1:3,000; gift of Dr. $R$. Chance, Eli Lilly \& Co.).

1. Abbreviation used in this paper: $\mathrm{BrdU}, 5$-bromo-2'deoxyuridine.
Beta cell replication, individual beta cell area, and beta cell mass. Methods used for measurement of beta cell replication, area and mass have been described in detail (17). For beta cell replication, beta cells and BrdU-positive beta cells were counted using microscope (BH-2; Olympus Corp., Lake Success, NY) connected to a video camera with a black and white monitor. Results were expressed as the percentage of BrdU-positive beta cells. At least 1,200 cells were counted per graft or pancreas.

The mean cross sectional area of individual beta cells, a measure of beta cell size, was determined on immunoperoxidase-stained sections of grafts and isolated islets. For both grafts and isolated islets the beta cell nuclei on a random field were counted and the area of the beta cell tissue in that field measured with an electronic planimetry program (Sigma Scan; Jandel Scientific, Corte Madera, CA). The beta cell area was divided by the number of beta cell nuclei to calculate the area of the individual beta cells. As pointed out previously (17), the actual number of beta cells was higher than the number counted, since not all beta cells were sectioned across their nuclei and, therefore, the size of the beta cells was overestimated.

Beta cell mass was measured by point counting morphometry on immunoperoxidase-stained sections of graft and endogenous pancreas. Each section was covered systematically using a 48-point grid to obtain the number of intercepts over beta cells, over endocrine nonbeta cells, and over other tissue. In pancreatic sections intercepts over exocrine tissue and over nonpancreatic tissue were counted separately. The beta cell relative volume was calculated by dividing the intercepts over beta cells by intercepts over total tissue; then the beta cell mass was estimated by multiplying beta cell relative volume by graft weight. Endocrine nonbeta cell mass and pancreatic exocrine mass were obtained in the same way. The beta cell mass of the islets at the time of the transplantation was determined in 7 groups of 500 islets isolated on different days. Beta cell mass was obtained by multiplying the weight of the islets by the percentage of beta cell volume as derived from our data (92.7\%).

Statistical analysis. Results were expressed as mean and standard error of the mean ( $\bar{x} \pm \mathrm{SEM})$. For comparisons between two groups the unpaired Student's $t$ test (two tailed) was used and for multiple comparisons the one-way analysis of variance (ANOVA) was used. A $P$ value of $<0.05$ was considered significant.

\section{Results}

\section{Metabolic evolution after transplantation and pancreatectomy}

The body weight and blood glucose at critical time points (transplantation, pancreatectomy, and harvesting) are shown in Table II. The evolution of blood glucose throughout the experiment is summarized in Fig. 1. Pancreatectomy induced severe hyperglycemia in Px-Tx and Px groups. In contrast, in Tx-Px group hyperglycemia was prevented by the previous transplantation of 500 islets. Blood glucose in this group was not different from glucose in normal group or Tx group during 
Table II. Metabolic Characteristics of Experimental Groups at Different Time Points

\begin{tabular}{|c|c|c|c|c|c|c|}
\hline \multirow[b]{2}{*}{ Group } & \multicolumn{2}{|c|}{ Day of transplantation } & \multicolumn{2}{|c|}{ Day of pancreatectomy } & \multicolumn{2}{|c|}{ Day of harvesting } \\
\hline & $\begin{array}{c}\text { Body } \\
\text { weight }\end{array}$ & $\begin{array}{l}\text { Blood } \\
\text { glucose }\end{array}$ & $\begin{array}{l}\text { Body } \\
\text { weight }\end{array}$ & $\begin{array}{l}\text { Blood } \\
\text { glucose }\end{array}$ & $\begin{array}{l}\text { Body } \\
\text { weight }\end{array}$ & $\begin{array}{l}\text { Blood } \\
\text { glucose }\end{array}$ \\
\hline & $g$ & mmol/liter & $g$ & $\mathrm{mmol} / \mathrm{liter}$ & $g$ & mmol/liter \\
\hline $1(T x+P x)$ & $130 \pm 7$ & $6.11 \pm 0.3$ & $228 \pm 6$ & $6.11 \pm 0.3$ & $269 \pm 10$ & $6.44 \pm 0.3$ \\
\hline $2(P x+T x)$ & $255 \pm 3$ & $18.8 \pm 0.9$ & $218 \pm 3$ & $6.22 \pm 0.2$ & $308 \pm 6$ & $9.78 \pm 1.8$ \\
\hline $3(\mathrm{Tx})$ & $117 \pm 5$ & $5.17 \pm 0.2$ & - & - & $245 \pm 10$ & $5.83 \pm 0.2$ \\
\hline $4(\mathrm{Px})$ & - & - & $202 \pm 4$ & $6.50 \pm 0.2$ & $254 \pm 9$ & $14.5 \pm 0.2$ \\
\hline 5 (normal) & - & - & - & - & $279 \pm 11$ & $6.28 \pm 0.2$ \\
\hline
\end{tabular}

For groups 2 and 3 the values show mean body weight and blood glucose of animals killed 14 and $28 \mathrm{~d}$ after transplantation. Results are expressed as mean $\pm \mathrm{SEM}$.

the follow up. One rat, however, developed transient moderate hyperglycemia (blood glucose, $10.2 \mathrm{mM} /$ liter). Transplantation in already pancreatectomized rats (Px-Tx group) restored euglycemia (blood glucose, $<7.2 \mathrm{mM} /$ liter; mean plus $2 \mathrm{SD}$ of blood glucose in normal group) in 7 of 12 rats $14 \mathrm{~d}$ after Tx and in 5 of 6 rats $28 \mathrm{~d}$ after transplantation.

\section{Beta cell replication}

Transplanted beta cells. As shown in Fig. 2, beta cell replication was increased in transplanted islets from $\mathrm{Tx}-\mathrm{Px}$ group $(1.15 \pm 0.12 \%)$ compared with pancreatic islets from normal group $(0.38 \pm 0.05 \%)$ and with transplanted beta cells from PxTx group $(0.56 \pm 0.09 \%)$ and $T x$ group $(0.64 \pm 0.07 \%)(P$ $<0.001)$. Replication was not statistically different in Px-Tx, $\mathrm{Tx}$, and normal groups. However, in Px-Tx groups, when day 28 and 42 grafts were considered separately, replication was increased at day $28(0.81 \pm 0.12 \%)$ compared with day 42 $(0.33 \pm 0.04 \%)$ and with normal pancreatic islets $(P<0.001)$. Replication was similar in Tx group at days 14 and 28 after transplantation.

Endogenous pancreas. As shown in Fig. 3, in Tx-Px group beta cell replication in the pancreatic remnant was increased $(1.01 \pm 0.25 \%)$ compared with Px-Tx group $(0.49 \pm 0.11 \%), \mathrm{Tx}$ group $(0.40 \pm 0.11 \%)$, Px group $(0.65 \pm 0.18 \%)$, and normal group $(0.38 \pm 0.05 \%)(P<0.05)$. When experimental animals were analyzed individually, it was apparent that replication in transplanted beta cells and in pancreatic beta cells was similar

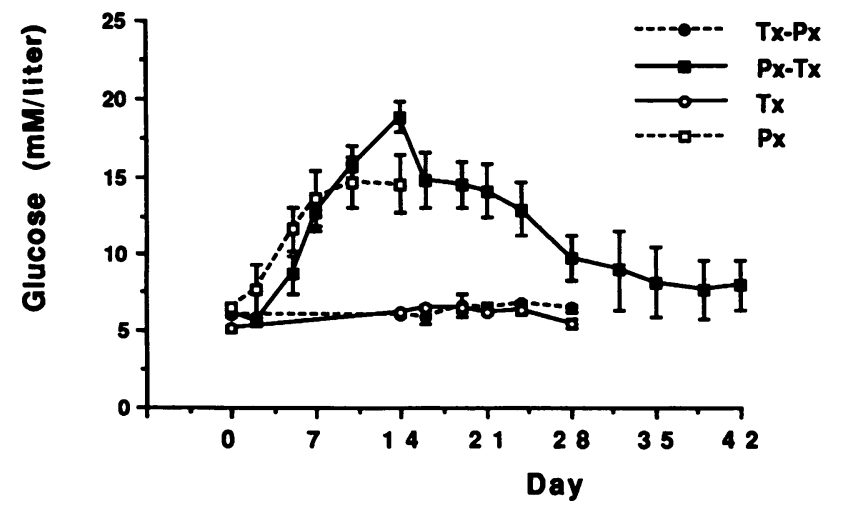

Figure 1. Evolution of fed blood glucose in experimental groups. Groups are described in Table I. Values are mean \pm SEM. and the presence of a positive correlation between replication in both locations was established $(r=0.55, P=0.003)$. However, in Px-Tx group replication was increased on day 28 in transplanted beta cells $(0.81 \pm 0.12 \%)$ but not in pancreatic beta cells $(0.55 \pm 0.18 \%)$. The discrepancy between replication in endogenous and transplanted islets in this group could reflect the different exposure to hyperglycemia, $\leq 14 \mathrm{~d}$ in transplanted islets and $>21 \mathrm{~d}$ in the endogenous islets (17).

\section{Beta cell area}

As shown in Fig. 4, the individual cross sectional area of beta cells in isolated islets was $239 \pm 10 \mu \mathrm{m}^{2}$. Beta cell size was increased in transplanted islets from Tx-Px group $\left(311 \pm 14 \mu \mathrm{m}^{2}\right)$ and Px-Tx group (328 $\left.\pm 13 \mu \mathrm{m}^{2}\right)$ compared with nonpancreatectomized group (Tx group: $252 \pm 12 \mu \mathrm{m}^{2}$ ) or with beta cell area in isolated islets $(P=0.001)$.

\section{Beta cell mass}

Transplanted islets. As shown in Fig. 5, transplanted beta cell mass increased in Tx-Px $(1.81 \pm 0.51 \mathrm{mg})$ and Px-Tx $(1.55 \pm 0.21 \mathrm{mg})$ rats compared with nonpancreatectomized animals (Tx group: $0.78 \pm 0.17 \mathrm{mg})(P<0.05)$. In Tx group one outlying value (higher than mean plus $2.5 \mathrm{SD}$ ) was ex-

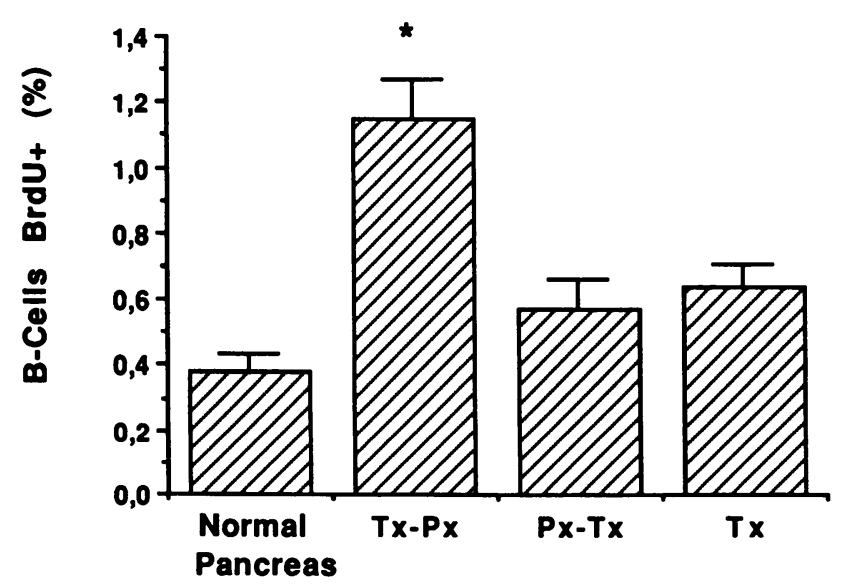

Figure 2. Beta cell replication in normal pancreas and in transplanted islets. Replication is expressed as percentage of BrdU-positive beta cells. Names on the $x$-axis correspond to groups shown in Table $\mathrm{I}$. Values are mean \pm SEM. ${ }^{*} P<0.001$ between Tx-Px group and all other groups. 


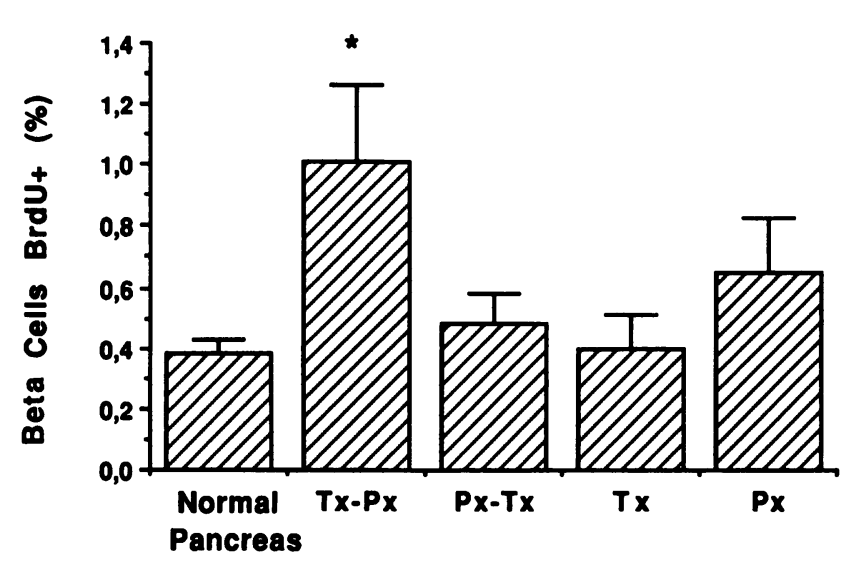

Figure 3. Beta cell replication in endogenous pancreatic beta cells. Replication is expressed as percentage of BrdU-positive beta cells. Names on the $x$-axis correspond to groups shown in Table I. Values are mean \pm SEM. ${ }^{*} P<0.001$ between Tx-Px group and all other groups.

cluded. Beta cell mass in Tx group grafts was reduced to $74 \%$ of the initially transplanted beta cell mass $(1.05 \pm 0.07 \mathrm{mg}, P$ $=$ NS).

Endogenous pancreas. Beta cell mass was not significantly different among the remnants of the three pancreatectomized groups or between the two nonpancreatectomized groups, despite the different protocols for transplantation (Table III). Beta cell mass in pancreatic remnants of Tx-Px and Px-Tx groups increased to 23 and $19 \%$, respectively, of the total beta cell mass in normal pancreases. In Px group the value represented $42 \%$ of the beta cell mass in normal pancreases. Beta cell mass in Tx group was similar to that of normal rats.

To compare the beta cell volume in the pancreas of all five groups beta cell mass was expressed per gram of pancreas ( Table III). Beta cell relative volume was increased in Px group compared with all other groups.

\section{Endocrine nonbeta cells and exocrine pancreas mass}

Differences in endocrine nonbeta cell mass of transplanted islets among groups did not reach statistical significance (results

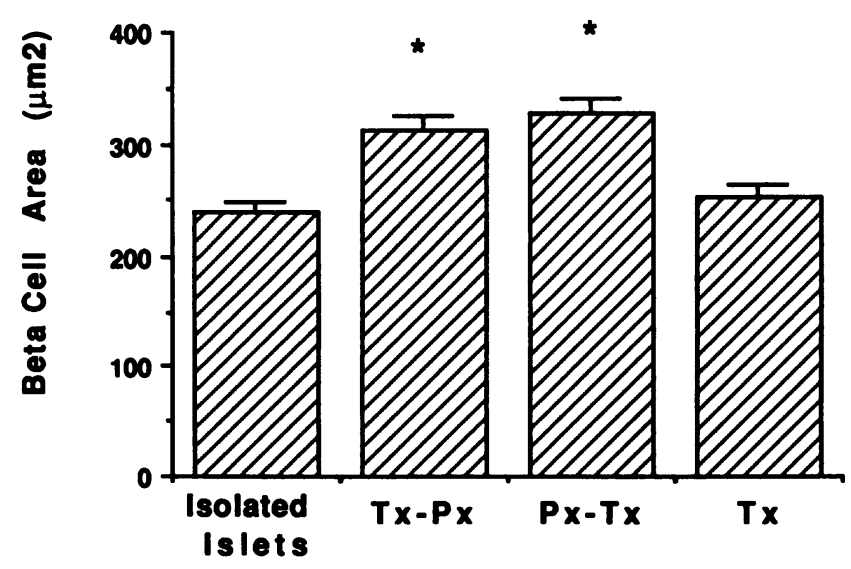

Figure 4. Area of individual beta cells from isolated and transplanted islets. Groups on the $x$-axis correspond to those described in Table I. Isolated islets show beta cell area on the transplantation day. Values are mean \pm SEM. ${ }^{*} P<0.001$ between Tx-Px and Px-Tx groups and isolated islets and Tx groups.

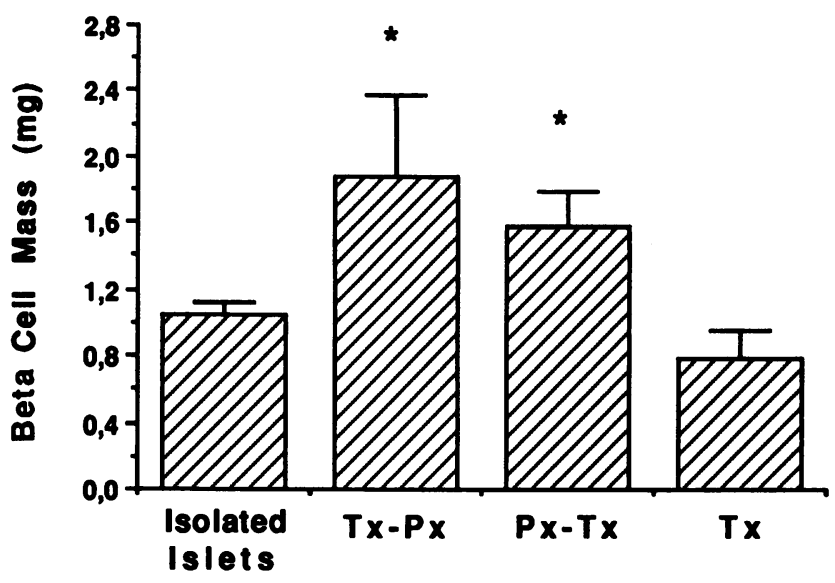

Figure 5. Transplanted beta cell mass. Groups on the $x$-axis correspond to those described in Table I. Isolated islets show the initially transplanted beta cell mass. Values are mean \pm SEM. ${ }^{*} P<0.05$, between Tx-Px and Px-Tx groups and Tx group.

not shown). Endocrine nonbeta cell mass in Tx-Px and Px-Tx groups was $\sim 10 \%$ that of normal pancreas. No differences were seen between $T x$ and normal groups.

The exocrine tissue showed a significant regeneration in pancreatectomized groups (Table III), attaining $15-17 \%$ of the exocrine mass in the normal group instead of the $5 \%$ remaining after surgery. The mass of exocrine tissue in the pancreatic remnant was similar in all three pancreatectomized groups, confirming that the extent of pancreatectomy was similar in all groups.

\section{Discussion}

Beta cells transplanted into normal rats increased their replication and size when a $95 \%$ pancreatectomy was performed ( TxPx group), and total beta cell mass almost tripled. Similar results were obtained when islets were transplanted into already pancreatectomized rats (Px-Tx group). However, although normoglycemia was maintained in Tx-Px rats after pancreatectomy, it took several days to restore it in Px-Tx group and in some cases this was not achieved. Beta cell response to pancreatectomy in the grafted islets was similar to that of islets in the endogenous pancreas, indicating that normal growth capacity was preserved in beta cells after transplantation.

Table III. Endocrine and Exocrine Mass in Pancreas and Pancreatic Remnants

\begin{tabular}{lcccc}
\hline \multicolumn{1}{c}{ Group } & Beta cell & Nonbeta cell & $\begin{array}{c}\text { Exocrine } \\
\text { pancreas }\end{array}$ & $\begin{array}{c}\text { Relative beta } \\
\text { cell volume }\end{array}$ \\
\hline & $m g$ & $m g$ & $m g$ & \\
$1(\mathrm{Tx}-\mathrm{Px})$ & $1.08 \pm 0.26$ & $0.15 \pm 0.05$ & $152 \pm 12$ & $6.95 \pm 1.70$ \\
$2(\mathrm{Px}-\mathrm{Tx})$ & $0.87 \pm 0.25$ & $0.13 \pm 0.04$ & $171 \pm 10$ & $4.83 \pm 1.30$ \\
$3(\mathrm{Tx})$ & $5.09 \pm 0.59$ & $1.29 \pm 0.16$ & $913 \pm 30$ & $5.55 \pm 0.58$ \\
$4(\mathrm{Px})$ & $1.99 \pm 0.75$ & $0.22 \pm 0.05$ & $150 \pm 14$ & $12.3 \pm 3.84^{*}$ \\
$5($ normal) & $4.68 \pm 0.65$ & $1.48 \pm 0.26$ & $977 \pm 30$ & $4.81 \pm 0.65$ \\
& & & & \\
\hline
\end{tabular}

Relative beta cell volume is beta cell mass per gram of pancreas. Values are mean \pm SEM. ${ }^{*} P<0.05$ compared with all other groups. 
The increase in replication and size of transplanted beta cells after pancreatectomy in Tx-Px rats resulted in increased beta cell mass. The severe hyperglycemia that followed pancreatectomy in Px and Px-Tx groups was prevented in Tx-Px rats by the transplantation of 500 islets. Thus, transplanted beta cells were able to compensate for the increased metabolic demand placed upon them by the surgical reduction of endogenous beta cell mass. It is not clear, however, how beta cells sensed this increased metabolic demand. The concept of adaptive beta cell proliferation has been used to suggest that functional demand is a mechanism of control of beta cell replication (23). Glucose is a well-known stimulus for beta cell replication both in vitro $(22,24)$ and in vivo $(25)$, and hyperglycemia is present in most of the conditions in which adaptive beta cell proliferation occurs. However, hyperglycemia was not detected in Tx-Px group. The results resemble the islet growth described in other situations of increased metabolic demand where hyperglycemia is not detected, such as $\mathbf{4 0}$ and $60 \%$ pancreatectomies $(20,21)$ or pregnancy $(26)$. Subtle elevations in blood glucose could have been responsible for increased beta cell replication in Tx-Px rats. Moreover, in addition to glucose, other mediators may also have contributed to increase beta cell proliferation. The identification of these mediators could open the possibility for interventions to modulate the growth of transplanted beta cells.

When islets were transplanted into already pancreatectomized rats (Px-Tx group) beta cell replication and size increased and beta cell mass doubled $14 \mathrm{~d}$ after transplantation. However, although transplanted and endogenous beta cell mass were similar in Tx-Px and Px-Tx groups, normoglycemia was sustained in Tx-Px rats throughout the follow up while its restoration was delayed, and in some case even not achieved, in Px-Tx rats. Since pancreatectomy in Tx-Px group was performed $14 \mathrm{~d}$ after transplantation, one could wonder whether an increase in grafted beta cell mass during that period was responsible for the maintenance of normoglycemia after pancreatectomy. The question was addressed by the measurement of beta cell mass in Tx group $14 \mathrm{~d}$ after transplantation. Beta cell mass in this group was found to be $74 \%$ of that initially transplanted, ruling out the possibility of an increased beta cell mass in Tx-Px rats at the time of pancreatectomy. The reduction confirms our previous results in mice showing that transplantation of islets into normal recipients results in a decreased beta cell mass in the graft after transplantation (17). Endogenous beta cell mass in the pancreas remnant was also similar in Tx-Px and Px-Tx rats. The extent of pancreatectomies was equivalent in both groups, as confirmed by the amount of exocrine tissue found at the end of follow up. Therefore, factors other than the absolute beta cell mass contributed to differences in blood glucose in these two groups. The previous observation that maintenance of normoglycemia may require a lower beta cell mass than its restoration (27) agrees with our current results in that a similar beta cell mass was able to sustain normoglycemia in Tx-Px rats but not to restore it in Px-Tx rats. Hyperglycemia, which is associated with insulin resistance, could have contributed to the differences in beta cell mass requirement. In addition, vascularization could have also played a role in the different evolution. It has been shown that transplanted islets are fully vascularized $10 \mathrm{~d}$ after transplantation $(28,29)$, and therefore islets transplanted into Tx-Px rats were well vascularized at the time of pancreatectomy. In con- trast, the islets transplanted into Px-Tx rats were confronted with hyperglycemia at the time of transplantation, when they had deficient vascularization. Impaired vascularization could reduce beta cell capacity to sense and respond to increased metabolic demand, and therefore decrease the functional beta cell mass. In a situation such our experimental groups, where only a marginal islet mass was transplanted $(30,31)$, vascularization of islets could have been crucial for an appropriate response to changes in metabolic conditions. Therefore, the delayed but eventual achievement of normoglycemia in most rats of Px-Tx group may have resulted from the combination of progressive increase in beta cell mass after transplantation and restoration of islet vascularization.

Beta cell replication and beta cell mass were also increased in the pancreatic remnant of Tx-Px and Px-Tx groups. Replication in transplanted and endogenous beta cells showed a good correlation in all three transplanted groups, suggesting that the responsiveness of transplanted beta cells was normal. The one exception was Px-Tx group $14 \mathrm{~d}$ after transplantation when beta cell replication was increased in the graft but not in the pancreatic remnant. The discrepancy could be due to different exposure times to severe hyperglycemia: $>21 \mathrm{~d}$ for endogenous pancreatic beta cells and $<14 \mathrm{~d}$ for transplanted beta cells. We have previously reported that the increased beta cell replication accompanying hyperglycemia did not persist when exposure to severe hyperglycemia became chronic (17). Similarly, replication was not significantly increased in Px rats in a situation of chronic severe hyperglycemia, suggesting again a limitation of beta cell replication.

Both beta cells and exocrine pancreas underwent significant regeneration after pancreatectomy. Beta cell mass and exocrine mass increased to a similar extent in Tx-Px and Px-Tx groups as shown by the preservation of the ratio between beta cell mass and pancreatic mass. The increase in exocrine tissue in Px group was equivalent to that in the other pancreatectomized groups, but beta cell mass increased more markedly in this nontransplanted group. Perhaps the presence of transplanted beta cells restrained the increase of endogenous beta cell mass in Tx-Px and Px-Tx groups.

The capacity of transplanted beta cells to respond to changes in metabolic demand and the similarity between their replicative response and that of endogenous nontransplanted beta cells have important implications for islet transplantation. In clinical transplantation, different factors may modify the metabolic demand placed on transplanted beta cells. For instance, episodes of acute rejection decrease the transplanted beta cell mass and higher doses of immunosuppressive drugs can increase insulin resistance and impair beta cell function or islet cell DNA replication $(32,33)$. It is therefore encouraging to find that transplanted beta cells are able to respond effectively to severe reductions in beta cell mass. Moreover, if the transplantation method could be optimized it may be possible to obtain a successful result with a smaller number of islets, thus alleviating the islet shortage that limits current transplantation efforts.

\section{Acknowledgments}

We thank J. Hollister, C. J. Cahill, and R. S. Schlesinger for expert technical assistance.

This work was supported by grants DK-35449 and DK-36836 from the National Institutes of Health and a grant from the Juvenile Dia- 
betes Foundation. E. Montaña was the recipient of a postdoctoral grant from the Ministry of Education and Science of Spain.

\section{References}

1. Scharp, D. W., P. E. Lacy, J. V. Santiago, C. S. McCullough, L. G. Weida, P. J. Boyle, L. Falui, P. Marchetti, C. Ricordi, R. L. Gingerich, et al. 1991. Results of our first nine intraportal islet allografts in type 1 , insulin-dependent diabetic patients. Transplantation (Baltimore). 51:76-86.

2. Warnock, G. L., N. M. Kneteman, E. Ryan, R. E. A. Seelis, A. Rabinovitch, and R. V. Rajotte. 1991. Normoglycemia after transplantation of freshly isolated and cryopreserved pancreatic islets in type 1 (insulin-dependent) diabetes mellitus. Diabetologia. 34:54-58.

3. Socci, C., L. Falqui, A. M. Davalli, C. Ricordi, S. Braghi, E. Bertuzzi, P. Maffi, A. Secchi, F. Gavazzi, M. Freschi, et al. 1991. Fresh human islet transplantation to replace pancreatic endocrine function in type I, insulin-dependent diabetic patients. Acta Diabetol. 28:151-157.

4. Gores, P. F., J. S. Najarian, E. Stephanian, J. J. Lloveras, S. Kelley, and D. E. R. Sutherland. 1993. Insulin independence in type I diabetes after transplantation of unpurified islets from a single donor with 15-deoxyspergualin. Lancet. 341:19-21.

5. Alejandro, R., R. G. Cutfield, F. L. Shienvold, K. S. Polonsky, L. Olson, J. Dillberg, J. Miller, and D. H. Mintz. 1986. Natural history of intrahepatic canine islet cells autografts. J. Clin. Invest. 78:1339-1348.

6. Warnock, G. L., and R. V. Rajotte. 1988. Critical mass of purified islets that induce normoglycemia after implantation into dogs. Diabetes. 37:467-470.

7. Warnock, G. L., K. D. Dabbs, M. G. Evans, M. S. Gattral, N. M. Kneteman, and R. V. Rajotte. 1990. Critical mass of islets that function after implantation in a large mammalian. Horm. Metab. Res. (Suppl. 25):156-161.

8. Kaufman, D. B., P. Morel, M. J. Field, S. R. Munn, and D. E. R. Sutherland. 1990. Importance of implantation site and number of islets transplanted on functional outcome following autotransplantation in a canine model. Horm. Me tab. Res. (Suppl. 25):162.

9. Weir, G. C., S. Bonner-Weir, and J. L. Leahy. 1990. Islet mass and function in diabetes and transplantation. Diabetes. 39:401-405.

10. Andersson, A., U. Eriksson, B. Petersson, L. Reibring, and I. Swenne. 1981. Failure of successful intrasplenic transplantation of islets from lean mice to cure obese-hyperglycemic mice, despite islet growth. Diabetologia. 20:237-241.

11. Swenne, I., and A. Andersson. 1984. Effect of genetic background on the capacity for islet cell replication in mice. Diabetologia. 27:464-467.

12. Mellgren, A., A. H. Schnell Landstrom, B. Petersson, and A. Andersson. 1986. The renal subcapsular site offers better growth conditions for transplanted mouse pancreatic islet cells than the liver or spleen. Diabetologia. 29:670-672.

13. Sandler, S., and A. Andersson. 1988. Stimulation of cell replication in transplanted pancreatic islets by nicotinamide treatment. Transplantation (Baltimore). 46:30-31.

14. Andersson, A., O. Korsgren, and P. Nasser. 1989. DNA replication in transplanted and endogenous pancreatic islets of obese-hyperglycemic mice at different stages of the syndrome. Metabolism. 38:974-978.

15. Dunger, A., O. Korsgren, and A. Andersson. 1990. DNA replication in mouse pancreatic islets transplanted subcapsularly into the kidney or intraportally into the liver. Transplantation (Baltimore). 49:686-689.
16. Serie, J. R., H. N. Cooper, K. A. Kemmer, and O. D. Hegre. 1992. Growth of neonatal islet transplants in the spontaneously diabetic BB/Wor rat. Diabetes. 41:1122-1129.

17. Montaña, E., S. Bonner-Weir, and G. C. Weir. 1993. Beta-cell mass and growth after syngeneic islet-cell transplantation in normal and streptozocin-diabetic C57BL/6 mice. J. Clin. Invest. 91:780-787.

18. Bonner-Weir, S., D. F. Trent, and G. C. Weir. 1983. Partial pancreatectomy in the rat and subsequent defect in glucose-induced insulin secretion. $J$. Clin. Invest. 71:1544-1553.

19. Brockenbrough, S., G. C. Weir, and S. Bonner-Weir. 1988. Discordance of exocrine and endocrine growth after $90 \%$ pancreatectomy in rats. Diabetes. 37:232-236.

20. Leahy, J. L., S. Bonner-Weir, and G. C. Weir. 1988. Minimal chronic hyperglycemia is a critical determinant of impaired insulin secretion after an incomplete pancreatectomy. J. Clin. Invest. 81:1407-1414.

21. Lee, H. C., S. Bonner-Weir, G. C. Weir, and J. L. Leahy. 1989. Compensatory adaptation of partial pancreatectomy in the rat. Endocrinology. 124:15111575.

22. Swenne, I. 1983. Effects of aging on the regenerative capacity of pancreatic beta-cells of the rat. Diabetes. 32:14-19.

23. Hellerstrom, C., I. Swenne, and A. Andersson. 1987. Islet cell replication and diabetes. In The Pathology of the Endocrine Pancreas in Diabetes. P. J. Lefebvre and D. G. Pipeleers, editors. Springer-Verlag, Heidelberg. 141-170.

24. Swenne, I. 1982. The role of glucose in the in vitro regulation of cell cycle kinetics and proliferation of fetal pancreatic B-cells. Diabetes. 31:754-760.

25. Bonner-Weir, S., D. Deery, J. L. Leahy, and G. C. Weir. 1989. Compensatory growth of pancreatic B-cells in adult rats after short term glucose infusion Diabetes. 38:49-53.

26. Parsons, N. A., T. C. Brelje, and R. L. Sorenson. 1992. Adaptation of islets of Langerhans to pregnancy: increased islet cell proliferation and insulin secretion correlates with the onset of placental lactogen secretion. Endocrinology. 130:1459-1466.

27. Ohzato, H., J. Porter, A. P. Monaco, E. Montaña, and T. Maki. 1993. Minimum number of islets required to maintain euglycemia and their reduced immunogenicity after transplantation into diabetic mice. Transplantation (Baltimore). 56:270-274.

28. Menger, M. D., J. Sabine, P. Walter, G. Feifel, F. Hammersen, and K. Messmer. 1989. Angiogenesis and hemodynamics of microvasculature of transplanted islets of Langerhans. Diabetes. 38(Suppl. 1):199-201.

29. Menger, M. D., P. Vajkoczy, R. Leidrer, S. Jager, and K. Messmer. 1992. Influence of experimental hyperglycemia on microvascular blood perfusion of pancreatic islet isografts. J. Clin. Invest. 90:1361-1369.

30. Tobin, B. W., J. T. Lewis, D. Z. X. Chen, and D. T. Finegood. 1993. Insulin secretory function in relation to transplanted islet mass in STZ-induced diabetic rats. Diabetes. 42:98-105.

31. Ryan, E. A., B. W. Tobin, J. Tang, and D. T. Finegood. 1993. A new model for the study of mild diabetes during pregnancy. Syngeneic islet-transplanted STZ-induced diabetic rats. Diabetes. 42:316-323.

32. Andersson, A., A. Borg, A. Hallberg, C. Hellerstrom, S. Sandler, and A. Schnell. 1984. Long-term effects of cyclosporin A on cultured mouse pancreatic islets. Diabetologia. 27:66-69.

33. Kojima, Y., S. Sandler, and A. Andersson. 1986. Cyclosporine inhibits mouse islet cell replication. Transplant. Proc. 18:37-39. 